\title{
Drought monitoring and early warning in China: a review of research to pave the way for operational systems
}

\author{
Lucy J. Barker ${ }^{1}$, Jamie Hannaford ${ }^{1,2}$, and Miaomiao Ma $^{3}$ \\ ${ }^{1}$ UK Centre for Ecology \& Hydrology, Wallingford, UK \\ ${ }^{2}$ Irish Climate and Research UnitS (ICARUS), Maynooth University, Maynooth, Ireland \\ ${ }^{3}$ Research Centre on Flood \& Drought Disaster Reduction of the Ministry of Water Resources, \\ China Institute of Water Resources and Hydropower Research, Beijing, China \\ Correspondence: Lucy J. Barker (lucybar@ceh.ac.uk)
}

Published: 16 September 2020

\begin{abstract}
Geographic and socio-economic factors combined make China particularly vulnerable to droughts. Here we review academic literature to assess publication trends on the topics of drought monitoring and early warning in China, exploring the common themes and recent advances presented. Literature searches for the 1970-2017 period were made for a range of search terms relating to drought monitoring. It was found that publications on these topics started to appear sporadically in 1989 and have increased rapidly since the early 2000s, with the rate of publication increasing over the last eight years. The scope of studies varied, often with the spatial scale considered: at the national scale, studies focused on evaluating existing indices, while new indices were developed and tested at the regional scale - relating, in general, to monitoring agricultural and meteorological droughts. At the catchment scale, novel monitoring techniques were developed, often incorporating other data types such as modelled data or soil moisture measurements. National scale operational drought monitoring in China is currently being improved and updated. However, although operational systems are discussed in the literature, there is a still a disconnect between theory and practice with the most recent advances not yet operationalised. Here, we identify the methods and approaches which can be translated from the experimental case study scale to the national operational scale.
\end{abstract}

\section{Introduction}

Unlike most other natural hazards, droughts can occur in any climatic region, are (often) slow to develop and can affect a large area. The wide range of spatial and temporal scales, in addition to the different parts of the hydrological cycle that can be affected, means impacts are wide ranging and can be costly (e.g. Mishra and Singh, 2010; Stahl et al., 2016; Tallaksen and Van Lanen, 2004; Wilhite, 2000). The interplay between socio-economic and physical factors (including the spatial distribution of water resources, population and agriculture) means China is particularly vulnerable to droughts. Over the past 60 years, drought affected on average 29 million people and $206000 \mathrm{~km}^{2}$ of farmland per year in China (State Flood Control and Drought Relief Headquarters of Ministry of Water Resources China, 2016). Agriculture is the sector worst affected by drought in China (He et al., 2011), with annual average crop yield losses of 16.3 billion kilograms. But there are also many severe socio-economic and environmental impacts listed on the Flood and Drought Disaster Bulletin for China each year (e.g. State Flood Control and Drought Relief Headquarters of Ministry of Water Resources China, 2016).

Effective monitoring and early warning (MEW) systems are integral to mitigating impacts and improving resilience to droughts. Drought management in China (including monitoring activities and the coordination of management and relief efforts) is led by the State Flood Control and Drought Relief Headquarters (FCDRHs) with support from additional ministries, local government and the FCDRH at various levels (state, provincial, municipal and county). Current drought monitoring tools in China are fed by a range of data sources and deliver drought monitoring products, including derived 
drought indices (Sayers et al., 2016). The China Drought and Flood Bulletin is published by the Ministry of Water Resources, and gives a retrospective review of the year.

Here, we review the proliferation of academic studies concerned with drought MEW in China in terms of publication trends, the common themes and recent advances. We end by outlining the steps required in order to make recommendations of methods and approaches which may be translated from experimental case studies to improve operational drought MEW in China.

\section{Data and methods}

In order to investigate publication trends on the topic of drought MEW in China (Sect. 3), several literature searches on publication topic and title were made using the following phrases using Web of Science (English) and the China Knowledge Resource Integrated Database (Chinese):

- drought monitoring China;

- drought indicators/index/indices China;

- drought early warning China.

The English literature was searched using Web of Science (http://webofknowledge.com, last access: 28 July 2020) and publications in the core collection between 1970 and 2017. The results of each search were then filtered to return only article publications (thereby excluding proceedings papers). The Chinese literature was also searched using the China Knowledge Resource Integrated Database (https:// www.cnki.net/, last access: 28 July 2020) using the same search terms with data up to the 25 May 2018 when the search was conducted. Results for the search "drought indicators/index/indices China" is hereafter referred to as "drought indices etc. China". Having reviewed some of the most highly cited papers on drought MEW in China in addition to some more recent papers, the common themes and recent advances in drought monitoring techniques and methods are discussed in Sect. 4 Common themes and Sect. 5 Recent advances. For brevity, we do not include all details of the literature surveyed here. Further details of the papers reviewed in this study can be found in Table 2 of Barker (2018) and Ma and Wang (2018), for the English and Chinese searches, respectively.

\section{Publication trends}

Table 1 shows the results in terms of numbers of publications of these search terms whilst Fig. 1 shows the cumulative number of publications per year returned for each search term.
A clear increase in the number of publications over time can be seen in Fig. 1, with the rate of publication on the topic of drought indices increasing dramatically in 2014. Figure 1 shows the total numbers of publications for each search term peaking in 2015 ("Drought early warning China") and 2017 ("Drought monitoring China" and "Drought Indices China") for all search results (all Publications), whilst when only articles were searched, for all three, the number of publications peaked in 2017.

There is a clear change in the proportion of results returned between all results and articles only results. The drought monitoring and drought indices searches begin with more proceedings paper and book chapters, with the number of articles increasing over time to a greater proportion of the total number of publications.

However, an overview of the titles of the returned publications do not always specifically mention these phrases. When publication title is searched, Fig. 1 shows that the number of publications returned reduces substantially. A much higher proportion of publications on the topic of drought indices also included the phrase in the title than those on the topic of drought monitoring or drought early warning.

A review of the Chinese literature revealed similar publication trends as those in the English academic literature. The majority of publications (when either topic or title was searched) related to drought monitoring, followed by drought indices. As with the search of the English literature, drought early warning returned the least results (Table 2). The first entries in the CNKI database were published in the late 1980s with a large increase in number after 2005, with numbers peaking in 2014 for drought monitoring and drought indices, and 2009 for drought early warning (Ma and Wang, 2018).

\section{Common themes}

Common themes, namely the purpose and spatial scale, and types of drought, identified from the papers are discussed in more detail below.

\subsection{Purpose and spatial scale}

Although the papers reviewed in Barker (2018) aimed to improve drought MEW through a better understanding of the drought hazard (such as a better understanding of the timing of drought propagation), the use of a new indicator or method, few/if any of the methods presented are used operationally in China (with the exception of Yan et al. (2016), although the Drought Watch reports are not yet publically available). This suggests that operational Chinese drought monitoring activities may be written up in the Chinese literature, and/or that there may remain a step of translating drought monitoring research into operational practices and that this research area has been driven by scientific endeavour rather than operational users. 
Table 1. Results from Web of Science for drought monitoring in China and associated search terms between 1970 and 2017 . The Max. column indicates the year with the highest number of publications for each search term, the number of publications is given with the year in brackets.

\begin{tabular}{|c|c|c|c|c|c|c|}
\hline \multirow[t]{2}{*}{ Search term } & \multicolumn{2}{|c|}{ Topic: all publications } & \multicolumn{2}{|c|}{ Topic: article only } & \multirow[b]{2}{*}{$\begin{array}{r}\text { Title: all } \\
\text { publications } \\
\text { Total }\end{array}$} & \multirow[b]{2}{*}{$\begin{array}{r}\text { Title: article } \\
\text { only } \\
\text { Total }\end{array}$} \\
\hline & Total & Max. & Total & Max. & & \\
\hline Drought monitoring China & 485 & 90 (2017) & 334 & 82 (2017) & 60 & 30 \\
\hline Drought early warning China & 57 & $15(2015)$ & 40 & 13 (2017) & 4 & 2 \\
\hline Drought indices etc. China & 1602 & 304 (2017) & 1371 & $289(2017)$ & 99 & 76 \\
\hline
\end{tabular}

Table 2. Results from CNKI researches for drought monitoring in China and associated search terms (after Ma and Wang, 2018). The Max. column indicates the year with the highest number of publications for each search term, the number of publications is given with the year in brackets.

\begin{tabular}{lrrrrrr}
\hline Search term & \multicolumn{2}{c}{ Topic } & & \multicolumn{2}{c}{ Title } \\
\cline { 2 - 3 } \cline { 5 - 6 } & Total & Max. & & Total & Max. \\
\hline Drought monitoring China & 1417 & $147(2014)$ & & 712 & $69(2014)$ \\
Drought early warning China & 296 & $51(2009)$ & & 175 & $32(2009)$ \\
Drought indices etc. China & 1440 & $137(2014)$ & & 666 & $63(2014)$ \\
\hline
\end{tabular}

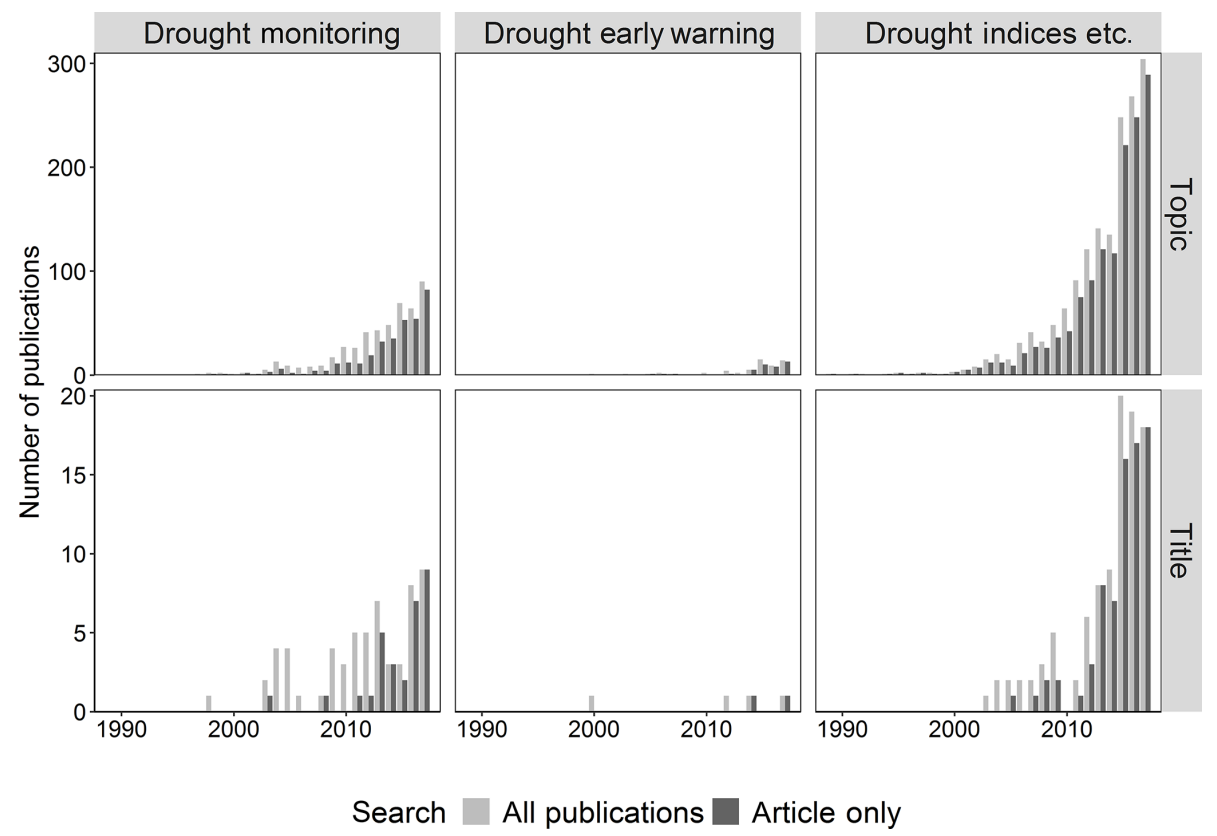

Figure 1. Number of publications each year in the period 1989-2017 for Web of Science search terms by both topic and title and for all publications from the search results and article only search results. Note the $y$ axis scale is different for each row to best show the range of data.

Six papers reviewed here used data for the whole of China, the remaining studies focussed on smaller regions (of varying sizes). Eight papers considered large-scale regions of China (such as northern China and south-west China), four papers the province level, whilst Wu et al. (2001) researched the best indicator for monitoring moisture conditions in four cities (Urumqi, Fuzhou, Beijing and Wuhan). Ten papers were concerned with drought monitoring at the catchment (river or lake) scale, and others geographical area such as the Guanzhong Plain or Loess Plateau (e.g. Bai et al., 2017; Zhao et al., 2015, respectively). 
Those considering the national scale tended to investigate the effectiveness of indices or remote sensing data for realtime drought monitoring (e.g. Guo et al., 2016; Wu et al., 2015), whilst Yu et al. (2014) assessed the spatio-temporal variation in drought characteristics across China and determined triggers and thresholds for monitoring and early warning. Regional studies mostly aimed to develop and test a new indicator (Hao et al., 2015; Wu et al., 2013; Zhang and Jia, 2013; Liu et al., 2015; Meng et al., 2016), with some regional and area studies aiming to analyse the performance of indices for monitoring agricultural drought (Bai et al., 2017; Wang et al., 2016). Catchment scale studies focussed on a range of issues, including: propagation timescales from meteorological to hydrological droughts (Wu et al., 2017; Ye et al., 2016), monitoring lake levels (Ding and Li, 2011), developing new indices for identifying regional/areal droughts (Fluixá-Sanmartín et al., 2018), developing thresholds for management (Zhao et al., 2016) and testing the operational Drought Watch system (Yan et al., 2016).

\subsection{Types of drought}

The complexity of defining drought has led to the definition of "types" of drought which relate to the compartment of the hydrological cycle in which deficits occur (Wilhite and Glantz, 1985). Deficits in precipitation are characterised as meteorological drought, soil moisture as agricultural drought and river flow or groundwater as hydrological drought. It recommended that meteorological drought indices should not be used to monitor other types of drought due to the nonlinear responses of hydrological processes to climate inputs (Van Loon and Van Lanen, 2012; Van Lanen et al., 2013). As such, drought-type specific indices should be used for operational monitoring (e.g. meteorological drought and precipitation; agricultural drought and soil moisture/vegetation condition; hydrological drought and streamflow/groundwater levels) for a full understanding of the drought hazard.

Given the importance of the agricultural sector in China, many papers in this brief review focussed on monitoring agricultural drought. Meteorological drought was the next most commonly monitored drought type, with most papers using observed rainfall data and one study (Zhang and Jia, 2013) using microwave data to monitor precipitation.

Hydrological drought (river flow) was not considered by many of the papers reviewed here, however, there were studies which compared the lag between meteorological and hydrological droughts (Ye et al., 2016; Wu et al., 2017) but did not discuss the use of the hydrological drought data directly for monitoring. However, these studies did provide an indication of timescales over which precipitation should be monitored in these catchments to reflect any deficits in streamflow where there may be a lack of easily available streamflow data for monitoring purposes. Wu et al. (2017) also illustrated how the operation of a reservoir may impact the lag between meteorological and hydrological drought. De- spite the reliance upon groundwater sources for water supply in northern China, only Long et al. (2014) included an assessment of groundwater storage (in a total water storage assessment using GRACE data), and so groundwater (hydrological) drought.

\section{Recent advances}

\subsection{Data sources}

Although many of the papers summarised in Barker (2018) used observed measurements of precipitation (in some cases gridded products) and temperature (with some using soil moisture or river flow observations), most did so in order to validate the results/indices produced using remotely sensed data. The most commonly used remote sensing data were MODIS (Normalised Difference Vegetation Index NDVI - and Land Surface Temperature - LST) and AVHRR (NDVI and LST), with other datasets including AMSR-E and GRACE. This perhaps reflects the wider availability and ease of accessing these data in comparison to point observations, particularly for large areas, or where observation points are scarce or data are not easily accessible. Zhang and Jia (2013) used microwave sensors to improve meteorological drought monitoring although remote sensing techniques have more commonly been used to monitor agricultural drought.

Modelled data were used by Zhang and Zhou (2015) in order to calculate the Standardised Moisture Anomaly Index (SZI) enabling water budget simulations to be incorporated within the indicator. This meant that the SZI agreed with observed streamflow better than meteorological drought indices like the Standardised Precipitation Index (SPI) and Standardised Precipitation Evapotranspiration Index (SPEI). Elsewhere, modelled data have been used to monitor regions with sparse observations, for example modelled hydrological data are used in the High Resolution South Asia Drought Monitor (although does not include China; https://sites.google.com/a/iitgn.ac.in/high_resolution_ south_asia_drought_monitor/streamflow-monitoring, last access: 28 July 2020). Li et al. (2015) used the Xin'anjiang model to derive variables to calculate the Multivariate Drought Index (MDI), however, they note that many of the required variables could be obtained from observations if available (e.g. precipitation, soil moisture and runoff).

The input and calibration data needed to calculate the SZI and other modelled monitoring outputs, in addition to the computational effort of processing the data (an issue also applicable to the use of remotely sensing data for monitoring) should be considered for an operational monitoring system in need of reliable, regular updates. The simple calculation of SPI, requiring only one data input, was a contributing factor to the World Meteorological Organisation recommending the use of the SPI for monitoring meteorological droughts (Hayes et al., 2011). Table 2 includes Ding and $\mathrm{Li}$ (2011) where satellite imagery was used to calculate lake 
water area, which was used with observed lake level data to calculate the water storage change. Long et al. (2014) developed a method whereby GRACE data could be used to monitor (and forecast) total water storage availability, but few studies used observed hydrological (river flow/groundwater) data directly for monitoring. In other cases, soil moisture observations were used (e.g. Bai et al., 2017; Su et al., 2003), Fluixá-Sanmartín et al. (2018) used a catalogue of drought impacts to verify droughts identified from indicator time series, whilst Wang et al. (2016) used winter wheat yields to identify the best indicator for agricultural drought monitoring.

\subsection{Combined indices}

Of the papers reviewed here which proposed new indices (nine papers and 11 new indices - marked with an asterisk in Table 2 of Barker, 2018), all proposed a combined indicator designed to monitor several aspects of the water cycle, or combine data and information to better characterise a particular type of drought. Most aimed to improve agricultural drought monitoring, but some (e.g. Li et al., 2015) aimed to improve drought monitoring of meteorological, agricultural and hydrological droughts using the MDI. The optimised combined indices developed by Hao et al. (2015) performed better and were more highly correlated with SPI-1 and SPEI-3 (derived from point observations) than individual remotely sensed indices. The SZI developed by Zhang and Zhou (2015) was more comparable to streamflow and the NDVI as it included evapotranspiration, runoff and soil moisture changes in its combination of the Palmer Drought Severity Index and the SPEI. The integrative aim of these combined indices is laudable, however, the added complexity to interpret and computational effort of calculating such combined indices should be assessed for an operational drought MEW system which requires fast, regular updates.

\section{Conclusion}

It is clear there is a large volume of material in the English and Chinese literature aiming to improve drought monitoring in China, with dramatic increases in the numbers of publications since the mid-2000s - particularly on the topic of drought indices. The importance of agricultural drought was reflected in the number of papers addressing this type of drought, specifically through the development of new indices attempting to improve agricultural drought monitoring. The increasing use of remote sensing data is evident, as is its use in the calculation of combined drought indices. The searches for "drought early warning China" returned few results in both the English and Chinese literature (Tables 1 and 2), and the papers reviewed here did not discuss the application of indices in early warning activities in order to forecast drought hazard or impacts.
In order to provide recommendations for operational drought MEW services, it will be necessary to undertake a broader literature search and assimilate results from searches of the English and Chinese literature in addition to a review of the tools and indices currently used to monitor droughts in China. Following these review activities, it will also be necessary to understand stakeholder needs (including local government, different levels of the FCDRHs etc.) for monitoring in terms of spatial and temporal resolution of data, time scales, the types of drought and indices and finally data visualisation. Crucial to this is understanding what data are available in real-time to support drought monitoring in China. However, an effective drought MEW system should provide information at a range of spatial scales (preferably from national to local scales, as well as integrating targeted local monitoring information into national scale drought alert and management systems) and a range of time scales (short term, for monitoring agricultural drought which can start quickly, to long term for monitoring hydrological droughts which may take longer to emerge). Understanding how drought indices link to drought impacts (e.g. Bachmair et al., 2016) is particularly important to ensure MEW tools can be used and interpreted in a way that enables appropriate actions to be taken in order to mitigate impacts. Through ongoing collaborations between Chinese and UK partners, these steps will be addressed going forwards to provide recommendations for operational drought MEW in China.

Data availability. No data sets were used in this article.

Author contributions. LJB, JH and MM discussed and developed the aims of the paper. LJB was responsible for the data analysis and visualisation. LJB prepared the original paper with contributions from $\mathrm{JH}$ and $\mathrm{MM}$.

Competing interests. The authors declare that they have no conflict of interest.

Special issue statement. This article is part of the special issue "Hydrological processes and water security in a changing world". It is a result of the 8th Global FRIEND-Water Conference: Hydrological Processes and Water Security in a Changing World, Beijing, China, 6-9 November 2018.

Acknowledgements. This study is an outcome of the NCODA Sustainable Use of Natural Resources to Improve $\mathrm{Hu}-$ man Health and Support Economic Development (SUNRISE) project (NE/R000131/1) and the National Key R \& D Program of China (2017YFC1502406). 
Financial support. This research has been supported by the Natural Environment Research Council (grant no. NE/R000131/1) and the National Key R\&D Program of China (grant no. 2017YFC1502406).

\section{References}

Bachmair, S., Svensson, C., Hannaford, J., Barker, L. J., and Stahl, K.: A quantitative analysis to objectively appraise drought indicators and model drought impacts, Hydrol. Earth Syst. Sci., 20, 2589-2609, https://doi.org/10.5194/hess-20-2589-2016, 2016.

Bai, J.-J., Yu, Y., and Di, L.: Comparison between TVDI and CWSI for drought monitoring in the Guanzhong Plain, China, J. Integr. Agricult., 16, 389-397, https://doi.org/10.1016/S20953119(15)61302-8, 2017.

Barker, L. J.: SUNRISE: Drought Monitoring in China A Brief Review, Centre for Ecology \& Hydrology, Wallingford, UK, 2018.

Ding, X. and Li, X.: Monitoring of the water-area variations of Lake Dongting in China with ENVISAT ASAR images, Int. J. Appl. Earth Obs. Geoinf., 13, 894-901, https://doi.org/10.1016/j.jag.2011.06.009, 2011.

Fluixá-Sanmartín, J., Pan, D., Fischer, L., Orlowsky, B., GarcíaHernández, J., Jordan, F., Haemmig, C., Zhang, F., and Xu, J.: Searching for the optimal drought index and timescale combination to detect drought: a case study from the lower Jinsha River basin, China, Hydrol. Earth Syst. Sci., 22, 889-910, https://doi.org/10.5194/hess-22-889-2018, 2018.

Guo, H., Bao, A. M., Liu, T., Chen, S., and Ndayisaba, F.: Evaluation of PERSIANN-CDR for Meteorological Drought Monitoring over China, Remote Sens., 8, 379, https://doi.org/10.3390/rs8050379, 2016.

Hao, C., Zhang, J., and Yao, F.: Combination of multi-sensor remote sensing data for drought monitoring over Southwest China, Int. J. Appl. Earth Obs. Geoinf., 35, 270-283, https://doi.org/10.1016/j.jag.2014.09.011, 2015.

Hayes, M., Svoboda, M., Wall, N., and Widhalm, M.: The Lincoln declaration on drought indices: universal meteorological drought index recommended, B. Am. Meteorol. Soc., 92, 485-488, 2011.

He, B., Lü, A., Wu, J., Zhao, L., and Liu, M.: Drought hazard assessment and spatial characteristics analysis in China, J. Geogr. Sci., 21, 235-249, https://doi.org/10.1007/s11442-011-0841-x, 2011.

Li, Q., Zeng, M., Wang, H., Li, P., Wang, K., and Yu, M.: Drought assessment using a multivariate drought index in the Huaihe River basin of Eastern China, in: Extreme Hydrological Events, edited by: Cudennec, C., Eicker, A., Pilon, P., Stoffel, M., Viglione, A., and Xu, Z., Proc. Int. Assoc. Hydrolog. Sci., 369, 61-67, 2015.

Liu, M., Yang, S. Q., Huang, H., He, H. X., Li, S. J., and Cui, Y.: Joint use of soil moisture and vegetation growth condition by remote sensing on the agricultural drought monitoring, in: MIPPR 2015: Remote Sensing Image Processing, Geographic Information Systems, and Other Applications, edited by: Liu, J. and Sun, H., International Society for Optics and Photonics, 9815, 98151T, 2015.

Long, D., Shen, Y., Sun, A., Hong, Y., Longuevergne, L., Yang, Y., Li, B., and Chen, L.: Drought and flood monitoring for a large karst plateau in Southwest China using extended GRACE data, Remote Sens. Environ., 155, 145-160, https://doi.org/10.1016/j.rse.2014.08.006, 2014.
Ma, M. and Wang, Y.: Drought monitoring research in China: a brief review based on the CNKI database analysis, China Institute of Water Resources and Hydropower Research, Beijing, China, 2018.

Meng, L. K., Dong, T., and Zhang, W.: Drought monitoring using an Integrated Drought Condition Index (IDCI) derived from multi-sensor remote sensing data, Nat. Hazards, 80, 1135-1152, https://doi.org/10.1007/s11069-015-2014-1, 2016.

Mishra, A. K. and Singh, V. P.: A review of drought concepts, J. Hydrol., 391, 202-216, 2010.

Sayers, P., Yuanyuan, L., Moncrieff, C., Jianqiang, L., Tickner, D., Xiangyu, X., Speed, R., Aihua, L., Gang, L., and Bing, Q.: Drought risk management: a strategic approach, UNESCO on behalf of WWF, Paris, 2016.

Stahl, K., Kohn, I., Blauhut, V., Urquijo, J., De Stefano, L., Acácio, V., Dias, S., Stagge, J. H., Tallaksen, L. M., Kampragou, E., Van Loon, A. F., Barker, L. J., Melsen, L. A., Bifulco, C., Musolino, D., de Carli, A., Massarutto, A., Assimacopoulos, D., and Van Lanen, H. A. J.: Impacts of European drought events: insights from an international database of text-based reports, Nat. Hazards Earth Syst. Sci., 16, 801-819, https://doi.org/10.5194/nhess-16-801-2016, 2016.

State Flood Control and Drought Relief Headquarters of Ministry of Water Resources China: The statistics of Flood and Drought Disaster Bulletin in China, Beijing, 2016.

Su, Z., Yacob, A., Wen, J., Roerink, G., He, Y., Gao, B., Boogaard, H., and van Diepen, C.: Assessing relative soil moisture with remote sensing data: theory, experimental validation, and application to drought monitoring over the North China Plain, Phys. Chem. Earth Pt. A/B/C, 28, 89-101, https://doi.org/10.1016/S1474-7065(03)00010-X, 2003.

Tallaksen, L. M. and Van Lanen, H. A. (Eds.): Hydrological drought: processes and estimation methods for streamflow and groundwater, in: Vol. 48, Elsevier, 2004.

Van Lanen, H., Wanders, N., Tallaksen, L., and Van Loon, A.: Hydrological drought across the world: impact of climate and physical catchment structure, Hydrol. Earth Syst. Sci., 17, 1715-1732, https://doi.org/10.5194/hess-17-1715-2013, 2013.

Van Loon, A. F. and Van Lanen, H. A. J.: A process-based typology of hydrological drought, Hydrol. Earth Syst. Sci., 16, 19151946, https://doi.org/10.5194/hess-16-1915-2012, 2012.

Wang, H. S., Vicente-Serrano, S. M., Tao, F. L., Zhang, X. D., Wang, P. X., Zhang, C., Chen, Y. Y., Zhu, D. H., and El Kenawy, A.: Monitoring winter wheat drought threat in Northern China using multiple climate-based drought indices and soil moisture during 2000-2013, Agr. Forest Meteorol., 228, 1-12, https://doi.org/10.1016/j.agrformet.2016.06.004, 2016.

Wilhite, D. A.: Drought as a natural hazard: concepts and definitions, in: A Global Assessment, Vol. I, chap. 1, edited by: Wilhite, D. A., Routledge, London, 3-18, 2000.

Wilhite, D. A. and Glantz, M. H.: Understanding: the drought phenomenon: the role of definitions, Water Int., 10, 111-120, 1985.

Wu, H., Hayes, M. J., Weiss, A., and Hu, Q.: An evaluation of the Standardized Precipitation Index, the China- $Z$ Index and the statistical Z-Score, Int. J. Climatol., 21, 745-758, https://doi.org/10.1002/joc.658, 2001.

Wu, J., Zhou, L., Liu, M., Zhang, J., Leng, S., and Diao, C.: Establishing and assessing the Integrated Surface Drought Index (ISDI) for agricultural drought monitoring in mid- 
eastern China, Int. J. Appl. Earth Obs. Geoinf., 23, 397-410, https://doi.org/10.1016/j.jag.2012.11.003, 2013.

Wu, J., Zhou, L., Mo, X., Zhou, H., Zhang, J., and Jia, R.: Drought monitoring and analysis in China based on the Integrated Surface Drought Index (ISDI), Int. J. Appl. Earth Obs. Geoinf., 41, 2333, https://doi.org/10.1016/j.jag.2015.04.006, 2015.

Wu, J., Chen, X., Yao, H., Gao, L., Chen, Y., and Liu, M.: Nonlinear relationship of hydrological drought responding to meteorological drought and impact of a large reservoir, J. Hydrol., 551, 495-507, https://doi.org/10.1016/j.jhydrol.2017.06.029, 2017.

Yan, N. N., Wu, B. F., Boken, V. K., Chang, S., and Yang, L. D.: A drought monitoring operational system for China using satellite data: design and evaluation, Geomat. Nat. Hazards Risk, 7, 264277, https://doi.org/10.1080/19475705.2014.895964, 2016.

Ye, X. C., Li, X. H., Xu, C. Y., and Zhang, Q.: Similarity, difference and correlation of meteorological and hydrological drought indices in a humid climate region - the Poyang Lake catchment in China, Hydrol. Res., 47, 1211-1223, https://doi.org/10.2166/nh.2016.214, 2016.
Yu, M., Li, Q., Hayes, M. J., Svoboda, M. D., and Heim, R. R.: Are droughts becoming more frequent or severe in China based on the Standardized Precipitation Evapotranspiration Index: 1951-2010?, Int. J. Climatol., 34, 545-558, https://doi.org/10.1002/joc.3701, 2014.

Zhang, A. and Jia, G.: Monitoring meteorological drought in semiarid regions using multi-sensor microwave remote sensing data, Remote Sens. Environ., 134, 12-23, https://doi.org/10.1016/j.rse.2013.02.023, 2013.

Zhang, L. and Zhou, T.: Drought over East Asia: A Review, J. Climate, 28, 3375-3399, https://doi.org/10.1175/jcli-d-14-00259.1, 2015.

Zhao, H., Gao, G., An, W., Zou, X., Li, H., and Hou, M.: Timescale differences between SC-PDSI and SPEI for drought monitoring in China, Phys. Chem. Earth Pt. A/B/C, 102, 48-58, https://doi.org/10.1016/j.pce.2015.10.022, 2015.

Zhao, J., Xu, J., Xie, X., and Lu, H.: Drought monitoring based on TIGGE and distributed hydrological model in Huaihe River Basin, China, Sci. Total Environ., 553, 358-365, https://doi.org/10.1016/j.scitotenv.2016.02.115, 2016. 